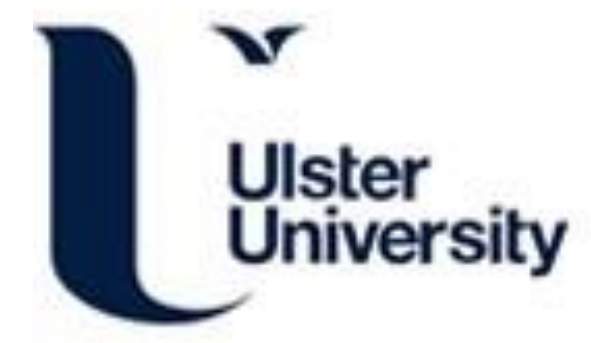

\title{
Social Welfare and Coercion in Public Finance
}

Winer, S., Tridimas, G., \& Hettich, W. (2014). Social Welfare and Coercion in Public Finance. In S. Winer, \& J. Martinez-Vazquez (Eds.), Coercion and Social welfare in Public Finance. Economic and Political Perspectives (pp. 160-194). Cambridge University Press.

Link to publication record in Ulster University Research Portal

\section{Published in:}

Coercion and Social welfare in Public Finance. Economic and Political Perspectives

Publication Status:

Published (in print/issue): 01/01/2014

\section{Document Version \\ Author Accepted version}

\section{General rights}

Copyright for the publications made accessible via Ulster University's Research Portal is retained by the author(s) and / or other copyright owners and it is a condition of accessing these publications that users recognise and abide by the legal requirements associated with these rights.

\section{Take down policy}

The Research Portal is Ulster University's institutional repository that provides access to Ulster's research outputs. Every effort has been made to ensure that content in the Research Portal does not infringe any person's rights, or applicable UK laws. If you discover content in the Research Portal that you believe breaches copyright or violates any law, please contact pure-support@ulster.ac.uk. 


\title{
Social Welfare and Coercion in Public Finance
}

\author{
Stanley L. Winer ${ }^{\mathrm{a}}$, George Tridimas ${ }^{\mathrm{b}}$, and Walter Hettich ${ }^{\mathrm{c}}$
}

\begin{abstract}
This paper develops an expanded framework for social planning in which the existence of coercion stemming from the provision of public goods is explicitly acknowledged. Key issues concern the precise definition of coercion, its difference from redistribution, and its incorporation into normative analysis. We explore modifications to traditional rules for optimal fiscal policy in the presence of constraints on coercion and determine the degree of coercion implied by traditional social planning. In addition, the trade-off between social welfare and coercion is mapped under specific conditions and the implications of this tradeoff for normative policy choice are considered. Analysis of the trade-off suggests that democratic societies may be on a backward bending part, where the shadow price of coercion is negative and improvements in both social welfare and the degree of coercion may be possible.
\end{abstract}

Key words: Coercion, Wicksell, redistribution, optimal taxation, marginal cost of funds, public goods, collective choice

JEL Categories: D70, H10, H20, H21

a: School of Public Policy and Administration and Department of Economics, Carleton University, Ottawa, Canada K1S5B6. Tel: (613)520-2600 ext.2630. Fax: (613)520-2551. Email: StanleyWiner@cunet.carleton.ca

b: Department of Accounting, Finance and Economics, Ulster Business School, University of Ulster, Shore Road, Newtownabbey, Co. Antrim BT37 0QB, UK Tel.: +44(0)28 90368273; Fax: +44 (0) 2890 366847. E-mail: G.Tridimas@ulster.ac.uk

c: Department of Economics, California State University, Fullerton, E-mail: whettich@fullerton.edu 


\section{Social Welfare and Coercion in Public Finance}

\section{Introduction}

In their introductory essay, the editors of this volume analyze a stylized social choice situation to illustrate how coercion inevitably arises in any democratic state. It is useful to begin by recalling that example here: There is a group of people who have come together in a room for a common purpose and who must collectively set the temperature on a thermostat and then pay for the resulting use of energy. Inevitably, some end up too hot or too cold, and even those for whom the temperature is just right are generally unhappy with the balance between what they pay and what they get. ${ }^{1}$ Individuals were able to escape the situation only if they moved out of the building. However, if they stayed, they had to put up with the coercion implied by their assent to the collective decision.

The example embodies several essential aspects of coercion in the public economy. Although we shall only deal with one of these in this essay, it is useful to review all of them briefly to provide a broader context for our discussion. Individuals will voluntarily participate in a collectivity despite its coercive nature if joining makes them better off. This suggests a first focus, namely the analysis of why communities form, under what circumstances people will join or leave them, and the nature and determinants of coercion that may persist in the equilibria of different types of societies. A separate body of work has developed on this topic, including the essays in the first part of this volume. ${ }^{2}$ A second focus deals with the choice of decision rules once a community has been formed. Here the classic work in a public finance context is by Wicksell (1896) and Lindahl (1919). As pointed out in the editors' introductory essay, Wicksell's proposal for approximate unanimity stems from his desire to minimize coercion exercised via the public finances for members of a community while providing for their welfare. The mechanism design literature discussed in the previous essay by John Ledyard extensively studied the question of the existence under various conditions of the Wicksell-Lindahl solution, in which marginal tax prices are equal to individual marginal evaluations of the public good that is provided at its Pareto efficient level.

Buchanan and Tullock (1962) made a further contribution to this line of work by adding efficiency as a criterion in the choice of the decision rule and by considering the tradeoff between decision costs and coercion associated with alternative rules, while Breton (1996) examined the relationship between coercion and budgetary institutions. One should 
note, however, that these authors did not provide a definition of coercion that could serve as a basis for welfare comparisons among different fiscal systems or institutional forms of government.

After collective decision rules have been put in place, participants in any community are inevitably faced with coercion arising from policies chosen in an externally fixed decision framework. This third aspect of coercion, which has received the least attention in the public finance literature so far, is the major focus of this essay. One should note that in contrast to the previous essay, we assume that exit from the community is not a viable option.

The usual approach in such a context has been to assume the existence of a planner who chooses public outputs and imposes taxes so as to maximize a social welfare function. In the preceding example, he or she would set the temperature in the room and fix tax rates for all the participants under the assumptions that there is agreement on the nature of the welfare function to be optimized and that there is sufficient information to do so. Although the analysis of specific policies, such as taxation, in the social welfare tradition has been extensive and highly successful, the existing literature has not so far dealt with the measurement and evaluation of coercion implicit in the possible actions of a planner.

In this essay, we examine the nature and measurement of coercion in a planning context by focusing on the extent to which individuals are unhappy with the balance between what they pay in taxes and what they get from the public sector. In Section 2 we ask whether and how such coercion can be formally defined, why it is different from redistribution, and how it can be explicitly taken into account in the design of social plans by incorporating specially designed constraints into the planner's problem. We then proceed in Section 3 to reexamine the well-known problem of linear income taxation with a public good if coercion constraints are imposed.

A special concern of fiscal analysis is the trade-off between social objectives. Introduction of coercion constraints allows us to formally explore the implications for social welfare of varying the degree of coercion in policy design. We pursue this topic in Section 4 by considering the trade-off between social welfare and coercion, both in a general framework and in a more restricted model in which a trade-off curve is explicitly constructed. Here the degree of coercion implied by traditional social planning is calculated. 
Although the essay emphasizes policy analysis in a planning framework, it is important to realize that the use of coercion constraints also has applications in alternative institutional settings. Accordingly, in Section 4 we also compare a social plan with the outcome of a competitive electoral system by locating both on the same welfare-coercion trade-off curve. The analysis provides conditions under which electoral competition may lead society to a position on the downward sloping part of the trade-off, where social welfare is lower and the degree of coercion is higher than in the corresponding (coercion-unconstrained) social plan.

\subsection{Intellectual Antecedents}

Because the combination of social planning and a concern with coercion is unusual, it will be useful to consider the underlying ideas and literature somewhat further before beginning the formal analysis. In this regard, it should be noted that the design and implementation of constraints on the state has a long and distinguished history (see, for example, Gordon 1999 and Riker 1982). A concern with coercion has often arisen in the analysis of collective choice because individuals do not usually agree on the nature of the social objectives to be sought. For this reason at least, participation in communal affairs is often predicated on the preservation of rights that limit the scope of collective action. Concern with coercion also arises because of the desire to cope with the agency of politicians, bureaucrats, or the military and because of the possibility that some groups of citizens may coerce (or take advantage of) others using the collective choice process even in the absence of agency control problems. In this essay, we accept the premise that constraints on the ability of a collectivity to coerce individual citizens are desirable and explore how such constraints ought to influence the structure of the public finances.

A precursor to such an inquiry in public finance can be found in the work of Simons (1938), who was concerned with establishing tax rules that limit interference in the lives of citizens and the private economy while also serving distributional ends. Buchanan and Congleton (1998, ch. 8) have more recently developed this approach further, calling for imposition of a very simple proportional tax system without a demogrant as a way to limit possible coercion. However, these authors do not provide a measure of the coercion implied by their proposals. 
One should note that coercion can also be imposed in ways other than through the balance between what citizens get and what they pay in taxes, including, for example, through public administration (Alm, McClelland, and Schulze 1992), conscription (Levy, 1997), regulation of access to and limitation of the scope of private markets (Wiseman 1989), as well as through the legal system (Anderson 2006, Leiser 2008). In this essay, we set administration and other non-fiscal dimensions of public policy aside and confine the analysis to coercion arising from the balance between collectively provided goods, services or transfers received, and taxes paid.

We realize that imposing constraints on a planner derived from a concern with coercion extends the analysis beyond criteria generally accepted in the planning literature. It also takes us outside of traditional public choice analysis. There have been other attempts to explicitly link collective choice concerns with the planning approach to policy analysis by imposing appropriate constraints. Acemoglu et. Al (2008) have explored the nature of optimal fiscal policy rules when one acknowledges the existence of incentive compatibility constraints of politicians. ${ }^{3}$ Here we deal with a different aspect of normative political economy: coercion of some citizens by others exercised through collective choice and public policy - a problem that would arise even if somehow agency problems were absent.

The approach we take to acknowledging the importance of coercion in public finance differs from that of mechanism design in an interesting and important manner. A mechanism design approach, such as that employed by John Ledyard in the previous essay, starts with imposition of voluntary participation constraints for individuals, thus, requiring that people voluntarily assent to the fiscal conditions they are faced with, because they always have the option of leaving the community. However, many people do not want to leave, often because it is costly to do so, and may still object to coercive arrangements. What is at stake in this essay, then, is the nature of the community when citizens are committed for whatever reason to staying at "home."

In an earlier contribution that implicitly acknowledges the coercive aspects of collective fiscal choices, Boadway (2002) proposes to break the formulation of optimal policy into four stages: constitutional, legislative, implementation, and market response. At each step the analyst takes the results of previous stages, which will include aspects of collective choice, as given in the design of a social plan. The approach in this essay is 
consistent with such a framework, but it goes further by explicitly incorporating coercion constraints into an analysis that could be used at any relevant stage.

\section{A Formal Definition of Coercion in Public Finance}

We shall define coercion for an individual as the difference between this person's utility under what he or she regards as appropriate treatment by the public sector and the utility that he or she actually enjoys as a result of its operation. To make this definition concrete, it is necessary to explain what appropriate treatment means. In the public finance setting, there are two polar approaches to this issue, each corresponding to a particular view of the relationship between the individual and the state. ${ }^{4}$ The one we shall emphasize is what we shall call the individual-in-society definition in which, in terms of our original example, the individual citizen remains in the room submitting to, but critically judging, the outcome of the collective choice process. ${ }^{5}$

Formally, let the individual's actual tax share be $\tau_{j}=\frac{T_{j}}{P G}$, where $T_{j}$ is his or her total tax payment, with $T_{j}=t_{j} Y_{j}$ where $t_{j}$ is the income tax rate and $Y_{j}$ is income, and $P$ is the (assumed) constant supply price of the public good $G$, and assume, as in Buchanan (1968) and Breton $(1974,1996)$, that the individual believes he would pay this tax share if quantity adjustment were possible. Let $V_{j}$ be the actual indirect utility of individual $j$, and $V_{j}^{*}$ his maximum utility when he is free to choose the level of the public good $G^{*}{ }_{j}$ at the individual tax price $\tau_{j} P$. Then in the individual-in-society approach, an individual's coercion is defined as

$$
\left[V_{j}^{*}\left(G_{j}^{*}, W_{j}, \tau_{j} P\right)-V_{j}\right], \text { where } G_{j}^{*}=\underset{\{G\}}{\operatorname{argmax}} V_{j}\left(G, W_{j}, \tau_{j} P\right)
$$

where $W_{j}$ is the person's wage or ability. This definition is implicit in the work of Buchanan (1968) and Breton $(1974,1996){ }^{6}$ In a private competitive market, an individual takes price as given, and quantity adjusts so that he or she is always satisfied with what he or she pays for. The definition in (1) is motivated by this private market analogue. Here, the individual accepts that the tax price is determined by collective choice and would like to, but cannot, quantity adjust.It should be noted that the definition in (1) implies that, in general, the amount of coercion is simultaneously determined along with the parameters of the fiscal system. This holds whenever the extent of coercion is taken into account in deciding on the fiscal system 
and its implied tax prices, unless the counterfactual is specified independently of contemporaneous policy choices.

Figure 1 illustrates the individual-in-society definition. Here indifference curves in the $(t, G)$ space are constructed from the individual utility function $U=U(X, G)$ where $X$ is the sole private good, and $G$ is the actual level of public good, and the individual budget constraint is $X=Y(1-t)$ with $t$ the actual proportional tax rate levied on this citizen. ${ }^{7}$ Then, the slope of the indifference curves in $(\mathrm{t}, \mathrm{G})$ space is $d t / d G=\left(\frac{\partial U}{\partial G} / \frac{\partial U}{\partial X}\right) / Y=\left(M R S_{G X} / Y\right)>0$. Given his tax share $\tau_{j}$ the price of the public good $P$ and income $Y_{j}$, the individual would like $G_{j}^{*}$ rather than $G$ at an implied tax rate of $t_{j}^{*}=G_{j}^{*}\left(\tau_{j} P / Y_{j}\right)$ Coercion (1) is shown as the resulting difference in utility between the counterfactual and actual situations, $\left[V_{j}^{*}-V_{j}\right]$.

There is an alternative definition of coercion based on a counterfactual that is a polar opposite to the individual-in-society approach illustrated in the figure. One could think of individuals as judging social outcomes from a perspective in which they alone decide what is best for them and for others. In this individual-as-dictator approach (not shown in Figure 1), the counterfactual utility would be determined by maximizing the person's indirect utility subject to the government budget restraint that shows all feasible combinations of tax rates and actual public good levels. Because the counterfactual then involves a choice directly from the government budget constraint, there is never any simultaneity between the counterfactual and the actual operation of the public sector. In effect, then, as can be seen by looking at the optimization problems introduced later, the problem simplifies to optimizing social welfare with different weights on certain individuals. 


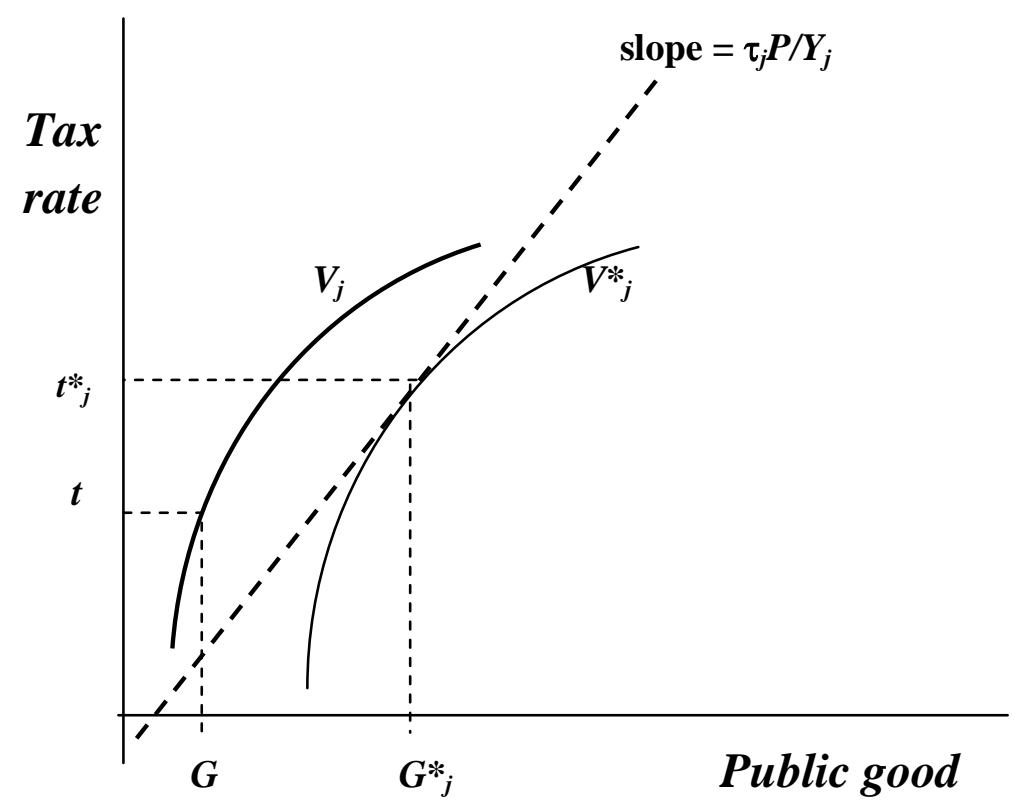

Figure 1: Coercion Using the Individual-in-Society Counterfactual

\section{Legend:}

$t:$ actual tax rate paid

$t_{j}^{*}=G_{j}^{*}\left(\tau_{j} P / Y_{j}\right):$ the implied income tax rate tax at which the individual-in-society is assumed to be able to quantity adjust the level of the public good, given his tax share $\tau_{j}$, the price of the public good $P$ and income $Y_{j}$

$G$ : actual level of the public good

$G_{j}^{*}$ : level of the public good that the individual would like the community to provide at his given tax price

$V_{j}^{*}$ : maximum desired utility at the individual's given tax price if that person could quantity adjust the level of the public good

$V_{j}^{*}-V_{j}$ : coercion when the individual-in-society counterfactual is adopted

The individual-as-dictator approach is more appropriate in studying situations in which individuals consider whether to join a group rather than for the third aspect of the coercion problem in which a community is already assumed to have formed. Moreover, it is interesting to confront the role of the counterfactual level of welfare in the definition of coercion throughout the analysis. For these reasons, we comment only briefly on the implications of adopting the individual-as-dictator approach in what follows. 
To understand the definition of coercion in (1), it is helpful to ask at this point why standard social planning does not take it into account, even though the difference between benefits and costs of public provision for each individual is reflected in individual indirect utilities and, therefore, in the social objective. The reason lies in the fact that the social planning approach posits no limits on the loss or gain in utility for particular individuals or groups occurring as part of a social plan. Any amount of redistribution required in the course of maximizing social welfare is implicitly regarded as acceptable - that is, as a matter of social solidarity with the planner's objective, regardless of the degree of coercion implied. (We shall return to the difference between coercion-constrained and socially optimal redistribution in Section 4, where a coercion-constrained social planner's optimization problem is formally compared to a traditional plan.)

It might be argued that application of the Pareto criterion - that only reallocations leaving every one better off are permissible - can attenuate concern with coercion. Strict application of the Pareto criterion limits the degree of individual coercion for moves from the status quo. It does not, however, alleviate any mismatch between benefits received and taxes paid that is embedded in the status quo itself. Moreover, much applied work using social welfare analysis goes beyond the strict Pareto criterion, which is too weak to allow for most social action, using the Kaldor-Hicks-Scitovsky potential compensation criterion instead. In that case, reallocations are considered desirable even if some people become worse off, as long as gainers could in principle more than compensate losers. For this reason, an explicit concern with coercion is justified and needed in most practical instances.

To see in general terms that coercion in public life is widely viewed as distinct from income redistribution, it is also instructive to consider the Bill of Rights in the United States and similar documents or unwritten constitutional rules in other countries. The rights afforded by these documents are intended to apply equally to the poor and rich; they were not created with reference to income levels but rather with reference to individual lives. There may, of course, be an interaction of redistribution as traditionally defined and coercion, but this only reinforces the insight that redistribution is not the sole origin of coercion. ${ }^{8} \mathrm{~A}$ similar point is emphasized by Wicksell(1896), who reminds us that an imperfect correspondence between what people pay in taxes and what they receive in a democratic society providing public 
services and collecting taxes differs from voluntary redistribution and should be a cause for concern. ${ }^{9}$

\subsection{Using Constraints to Model the Role of Coercion}

To develop a normative approach that allows us to compare and evaluate specific fiscal policies and electoral mechanisms in terms of the coercion and welfare they imply, we shall proceed by imposing coercion constraints on maximization of social welfare as usually defined. The use of constraints in this way may be defended on both conceptual and practical grounds.

We have already noted the long history of attempts to limit the power of politicians and coercion of some citizens by others through the fiscal system. The most important way in which limits on such activities have been introduced into political arrangements is by written or unwritten constitutional provisions restricting the power of government to abridge individual rights. Such provisions do not in principle allow for a trade-off between the rights that are given and other policy objectives. They may, of course, be subject to interpretation by the courts but always with the understanding that the rights take precedence over other public aims. The setting of boundaries or constraints on public action thus represents a wellknown and tested approach to dealing with coercion in public life.

A strict welfarist might argue that if it matters to an individual that he is being coerced, then this should be reflected in his or her utility function. And if it is, then social welfare maximization will take this concern into account. However, introducing coercion into a utility function is obviously a shorthand for a complicated social situation. ${ }^{10}$ It is hardly clear that this is the best way to proceed, even if using constraints appears to involve the introduction of a non-welfarist criterion.

Consider an analogy to modeling the social role of money. Macroeconomists have tried to come to grips with the role of money in society either by putting money into the utility function following Patinkin (1965) - an obvious approximation to the complex social role of money - or by adding constraints to the specification of the economy while continuing to model individual economic agents in a more or less traditional fashion (e.g., the cash-inadvance constraints of Clower 1967). Our approach is analogous to the second method. We add coercion constraints to a planning problem to incorporate an important aspect of 
collective choice in a simple and (we think) revealing manner. Although justification on the basis of the way in which boundaries on collective action are actually set seems to us sound, to an extent the approach we develop also reflects our judgment that it is a useful way to proceed in an important area of research in which little progress has so far been made. Our investigation remains essentially welfarist in intention, although in a broader context where a concern with limits on the degree of coercion is regarded as important for the social welfare of the community. ${ }^{11}$

Before we can specify the coercion constraints that are to be imposed on the planner, there are two additional matters to consider. First, there is the issue of whether we apply coercion constraints at the level of each individual, as implied by the use of the subscripts in definition (1), or at a group level. Although applying constraints to each individual is consistent with the tradition initiated by Wicksell, we also want to explore an approach that allows for stronger policy judgments and a greater degree of coercion. Although there is not a complete parallel, defining coercion over a group of individuals is similar to the use of the Kaldor-Hicks-Scitovsky (KHS) potential compensation criterion. In what follows, we mainly employ a constraint on aggregate coercion (its sum across individuals), which is analogous to the application of the KHS criterion. The corresponding analysis with individual constraints is provided in an Appendix.

Second, because the simultaneity of coercion and the actual (or planned) operation of the public sector can lead to considerable mathematical complexity, it proves useful for working out examples to approximate coercion by using levels of the public good - a method that follows Buchanan and Breton. The argument is illustrated in Figure 2. Because the marginal evaluation of the public good declines with the size of the public sector, the difference in utility in (1) is monotonically related to the difference between the level of the public good in the counterfactual and that provided by the operation of the public sector, $\left(G^{*}-G\right)$. To allow for cases in which the difference between $G$ and $G^{*}$ is sometimes negative and sometimes positive, we may use the square of the difference in public good levels as an index of coercion. ${ }^{12}$ Thus, people who want less of the public good in the counterfactual (illustrated in Figure 2) are treated symmetrically with those who would like more. This is so because in either case, the actual utility at given tax prices must be less than what it would be in the individual's preferred counterfactual. 
Figure 2: Coercion Measured by the Level of the Public Good

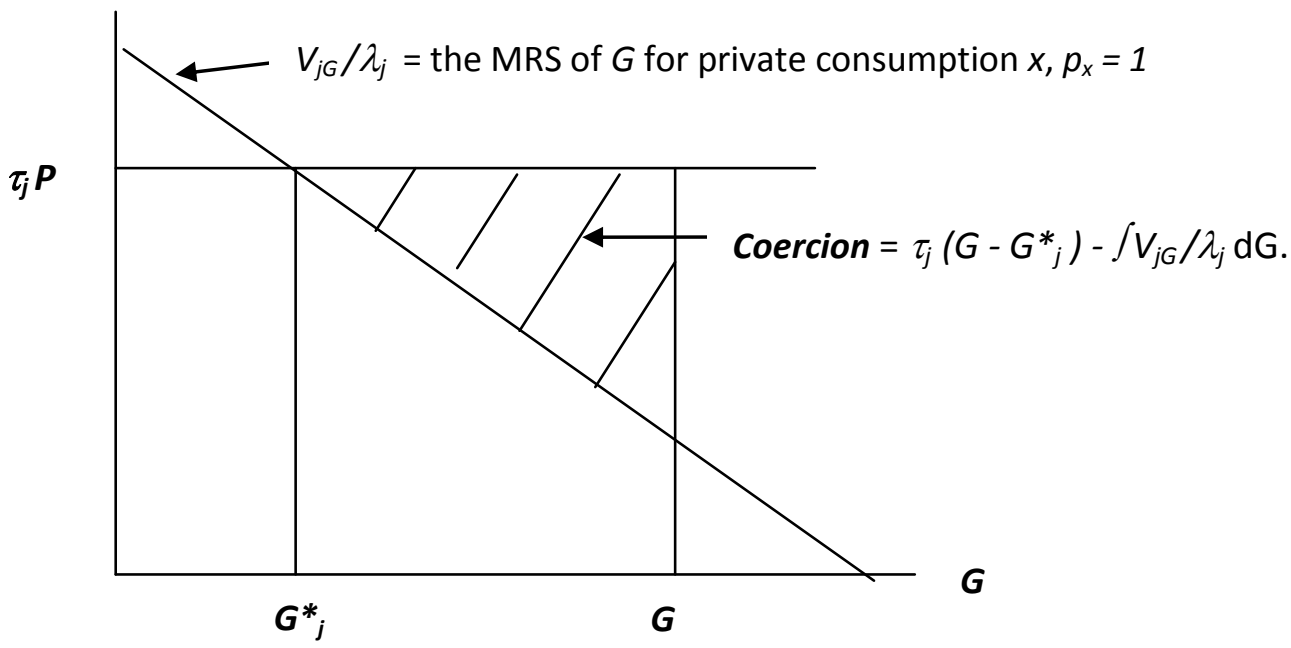

The different ways of specifying coercion constraints that have been pointed to are conveniently summarized in Table 1 , in which we use $K_{j}$ to denote the "degree" of coercion applied to individual $j$ (and, later, $\kappa$ for the associated shadow price) because the Greek word for coercion is katanagasmos. The constraints are specified in the table as inequalities, although in the following analysis we assume for mathematical convenience that coercion is applied up to the maximum allowed, so that in practice we deal only with equalities.

Table 1: Alternative Coercion Constraints Based on the Individual-in-society Definition of Coercion

\begin{tabular}{|l|l|l|}
\hline \multicolumn{3}{|c|}{ Type of coercion constraint } \\
\hline $\begin{array}{l}\text { Counterfactual or its Proxy Used } \\
\text { in the Definition }\end{array}$ & Individual $(j=1 \ldots N)$ & \multicolumn{1}{c|}{ Aggregate } \\
\hline $\begin{array}{l}\text { Utility if the individual could adjust } \\
\text { the level of the public good at the } \\
\text { prevailing tax-price }\end{array}$ & Case 1: & Case 2: \\
\hline $\begin{array}{l}\text { Desired level of the public good } \\
\text { given the prevailing tax-price. }\end{array}$ & $\left(V^{*_{j}}-V_{j}\right) \leq K_{j}$ & $\sum_{j}\left(V^{*_{j}}-V_{j}\right) \leq K$ \\
\hline
\end{tabular}

Legend:

$G_{j}^{*}$ : level of the public good that the individual would like the community to provide at his given tax price

$G$ : actual level of the public good provided

$K_{j}$ : the degree of coercion for citizen $j$. We note that the Greek word for coercion is katanagasmos.

$K$ : (unsubscripted) an aggregate level of coercion

$V_{j}^{*}$ : maximum desired utility at the individual's given tax price if that person could adjust the level of the public good

$V_{j}$ : actual level of utility 
In specifying how coercion will enter the analysis, in addition to coercion constraints one may want to acknowledge that coercion may serve as a method of reducing the costs of policy actions, such as that associated with the excess burden of taxation, thus having a productive as well as a harmful social role. We do not incorporate this possibility into the analysis. Excess burdens are defined in the usual manner, independently of the degree of coercion. ${ }^{13}$ The emphasis here is on defining coercion arising from the collective provision and financing of public goods and services, on investigating how limits to such coercion ought to alter the structure of optimal policy, and on comparing the degree of coercion implied by optimal policy with coercion that results from a collective choice process.

\section{Coercion-Constrained Optimal Linear Income Taxation with a Public Good}

Having offered a formal definition of coercion, we can now show how the introduction of coercion constraints alters the welfare analysis of a fiscal system in which a pure public good is financed with a linear income tax of the form $T_{j}=t Y_{j}-a .{ }^{14}$ We choose this application because it permits easy comparison with accepted results in the literature.

This investigation differs from that of earlier pioneers Simons (1938) and Buchanan and Congleton (1998). In one sense it is less general: they derive the nature of a fiscal system they regard as most efficient given the satisfaction of their concern to limit coercion. This is the genesis of Simons's advocacy of the broad base income tax, which by its breadth prevents governments from "dipping into great incomes with a sieve." By starting with a fiscal system of a particular type, we cannot replicate this sort of investigation. On the other hand, we shall be able to proceed with greater analytical depth with regard to the definition of coercion and its role in determining parameters of the fiscal system, allowing careful comparison of the coercion-constrained system with the traditional social plan as well as an investigation of the trade-off between coercion and social welfare.

Assume then that there are $N$ individuals indexed by $j$, each maximizing utility defined over a private good $X_{j}$, leisure $L_{j}$, and a public good $G$ and receiving a fixed wage $W_{j}$. The individual's optimization problem is

$$
\operatorname{Max} U_{j}=U_{j}\left(X_{j}, L_{j}, G\right) \text { subject to } X_{j}=(1-t) W_{j}\left(1-L_{j}\right)+a ; j=1, \ldots N
$$

where, in addition to previous definitions, $H_{j}$ is the supply of labor, with $L_{j}+H_{j}=1 .^{15}$ 
To establish the counterfactual, we consider the individual when he is free to choose the level of the public good $G_{j}$, given his (average) tax share $\tau_{j}$, which is assumed by the individual to be constant with respect to the level of the public good. This tax share is given by the ratio of the tax paid by $j$ to total tax revenue: $\tau_{j}=T_{j} / \Sigma_{j} T_{j}$. We note for later use that with the linear tax system this tax share is

$$
\tau_{j}=\frac{t Y_{j}-a}{t \Sigma_{j} Y_{j}-N a} .
$$

Because the marginal cost of the public good $P$ is constant, the actual tax price per unit of $G, \tau_{j} P$ is also the one that applies to marginal changes in public services when viewed from the perspective of each individual. The individual's optimization problem we can use to define his or her counterfactual then can be stated as

$$
\operatorname{Max} U_{j}=U_{j}\left(X_{j}, L_{j}, G_{j}\right) \text { subject to } X_{j}+\tau_{j} P G_{j}=W_{j}\left(1-L_{j}\right) \text {. }
$$

Solving the first order conditions, $U_{j X}=\lambda_{j}^{*}, U_{j L}=\lambda_{j}^{*} W_{j}$ and $U_{j G}=\lambda_{j}^{*} \tau_{j} P$, yields the counterfactual indirect utility $V_{j}^{*}$ in $(1)$, where the $\left(^{*}\right)$ reflects the fact that the individual is considered to be choosing his most preferred level of $G$ at the given tax price.

\subsection{Social Welfare Maximization under an Aggregate Coercion Constraint}

In choosing fiscal policy instruments, the coercion-constrained planner chooses $G, t$, and $a$ to solve the problem of maximizing social welfare subject to a budget restraint:

$$
\text { Max } S=\sum_{j} V_{j} \text { subject to } t \sum_{j} W_{j} H_{j}-N a=P G \text {. }
$$

In addition, the planner faces one or more coercion constraints. In this respect, for simplicity we consider case 2 in Table 1, in which coercion is defined using utility levels and aggregated across individuals. As we have already pointed out, this case is analogous to the use of the Kaldor-Hicks-Scitovsky criterion in cost-benefit analysis. The corresponding Lagrangean for the constrained social planning problem is

$$
L=\sum_{j} V_{j}+\mu\left[t \sum_{j} W_{j} H_{j}-N a-P G\right]+\kappa\left[K-\sum_{j}\left(V_{j}^{*}-V_{j}\right)\right]
$$


In solving this problem, $V^{*}$ and the shadow price of coercion $\kappa$ are determined simultaneously along with policy instruments, so the coercion constraint cannot be simply collapsed into a part $\left(V_{j}\right)$ that can be added to the social welfare function and a remainder that is constant and so can be ignored. In other words, as we pointed out earlier, acknowledging coercion does not amount to simply placing added weight on the utility of some individuals in a social plan. The reason is that a concern with coercion requires that weight be given to the counterfactual level of utility for each individual $V_{j}^{*}$.

By the envelope theorem, the shadow price of coercion $\kappa$ is equal to $d S^{*} / d K$, where the star denotes an optimal value. Social welfare will reach its maximum when this derivative is zero, at a corresponding and generally non-zero level of aggregate coercion $K$ (to be derived in the next section for a particular case). Welfare will then be equal to what it would be in the unconstrained or traditional social plan. Accordingly, we may say that when the shadow price is high, there will be a large payoff (in terms of social welfare) from solidarity with the aims of the unconstrained social planner. We shall consider the shadow price of coercion further in what follows, noting at this point only that the formulation of the coercion constraint in (6) does not ensure that it will always be positive, because $K$ may exceed the level of coercion that is consistent with the traditional social welfare optimum.

Using the definition of $V_{j}^{*}$, we have the first order conditions for the coercion constrained planner's problem:

$$
\begin{aligned}
& (1+\kappa) \sum_{j} \lambda_{j} W_{j} H_{j}=\mu\left[\sum_{j} W_{j} H_{j}+t \sum_{j} W_{j}\left(\frac{\partial H_{j}}{\partial t}\right)\right]+\kappa \sum_{j} \lambda_{j}^{*} P G_{j}^{*}\left(\frac{\partial \tau_{j}}{\partial t}\right) \\
& (1+\kappa) \sum_{j} \lambda_{j}=\mu\left[N-t \sum_{j} W_{j}\left(\frac{\partial H_{j}}{\partial a}\right)\right]-\kappa \sum_{j} \lambda_{j}^{*} P G_{j}^{*}\left(\frac{\partial \tau_{j}}{\partial a}\right) \\
& (1+\kappa) \sum_{j} \lambda_{j} m_{j}=\mu\left[P-t \sum_{j} W_{j}\left(\frac{\partial H_{j}}{\partial G}\right)\right]
\end{aligned}
$$

where $m_{j}$ is the marginal rate of substitution between public and private goods for person $j$, and $\lambda_{j}$ is his or her marginal utility of money. These equations feature two important new elements that are absent from traditional optimal taxation but that are always present in the analysis of coercion: 
1. the translation of tax structure into the tax price - appearing earlier as $\left(\frac{\partial \tau_{j}}{\partial t}\right)$ and $\left(\frac{\partial \tau_{j}}{\partial a}\right)$; and

2. the translation of the tax price into welfare via the demand for $G-\operatorname{shown}$ as $\lambda_{j}^{*} P G_{j}^{*}$

To explore the implications of these equations for fiscal structure, we first use them to characterize optimal coercion-constrained policy in a general manner. We begin with (3), which characterizes the coercion-constrained size of government. Define the covariance between the $\lambda_{j}$ and $m_{j}$ by $\sigma_{\lambda m}^{2}=\left(\Sigma_{j} \lambda_{j} m_{j} / N\right)-\left(\Sigma_{j} \lambda_{j} / N\right)\left(\Sigma_{j} m_{j} / N\right)$. Also define the means $\lambda=\Sigma_{j} \lambda_{j} / N$ and $\mathrm{m}=\Sigma_{j} m_{j} / N$, and the normalized covariance between $\lambda_{j}$ and $m_{j}$, $\delta=\sigma_{\lambda m}^{2} / \lambda \mathrm{m}$. The latter reflects the distributional characteristics of the public good.

Then substituting these definitions into (3) and manipulating yields a characterization of the optimal coercion-constrained level of the public good:

$$
\left(\Sigma_{j} m_{j}\right)(1+\delta)(1+\kappa)=\frac{\mu}{\lambda}\left(P-t \Sigma_{j} W_{j} \frac{\partial H_{j}}{\partial G}\right)
$$

Equation (8) is a generalization of the Samuelson condition as amended by Atkinson and Stiglitz (1974) to acknowledge a concern with coercion of some citizens by others through the fiscal system. The right-hand side is the familiar (coercion-unadjusted) social marginal cost of the public good net of the induced revenue effects of public provision on labor supply. ${ }^{17}$ The left-hand side represents the social marginal benefit from public provision in the presence of the coercion constraint. The first two terms here are also familiar: the sum of the marginal rates of substitution between private and public goods $\Sigma_{j} m_{j}$, and the term $1+\delta$ , which adjusts the marginal rates of substitution for the distributional characteristics of public good. The new term $(1+\kappa)$ reflects the effect of the coercion constraint and combines with $(1+\delta)$ to represent the average effect of coercion.

The traditional planning solution in the absence of a coercion constraint is derived by setting $\kappa=0$ in (8). Comparison of the implications for fiscal structure of (8) with those of the traditional formula is not straightforward however, as the solution depends on the level of coercion as well as on the relationship between $K$ and its shadow price, which is endogenous. We discuss the $\kappa-K$ relationship, the size of government, and the welfare-coercion tradeoff in the next section, where an extended example is explored. 
Condition (8) also shows that the coercion-adjusted marginal cost of funds (MCF) appropriate for policy analysis is $/[\lambda(1+\kappa)]$. This coercion-adjusted MCF will tend to be low when $\kappa$ is high - that is, when increasing $K$ to relax the coercion constraint has a large payoff in terms of social welfare. Again, the traditional formula is derived simply by setting the shadow price to zero. And although comparison with the two formulas is complicated by the endogeneity of $\kappa$, it should be noted that the MCF remains relevant in the present context as an analytical concept.

\subsection{The Optimal Coercion-Constrained Tax Rate}

To derive the optimal income tax rate in the presence of coercion, we proceed as follows. Multiplying (1) by $(1 / N)$ and (2) by $\left(\sum_{j} W_{j} H_{j} / N^{2}\right)$, subtracting the latter from the former, and using the Slutsky decomposition, $\partial H_{j} / \partial t=s_{j}-W_{j} H_{j}\left(\partial H_{j} / \partial a\right)$, yields

$$
(1+\kappa) \sigma_{\lambda Y}^{2}=t\left[\frac{\mu}{N} \Sigma_{j} W_{j} s_{j}-\sigma_{Y a}^{2}\right]+\frac{\kappa}{N} \Sigma_{j} \lambda_{j}^{*} P G_{j}^{*}\left(\frac{\partial \tau_{j}}{\partial t}+\frac{\partial \tau_{j}}{\partial a} \bar{Y}\right),
$$

where $Y_{j}=H_{j} W_{j}$ and the negative covariance $\sigma_{\lambda Y}^{2}$ shows the relationship between the marginal utility of income and income from work and reflect the distributional effects of income taxation. Covariance $\sigma_{\lambda Y}^{2}$ is negative because the higher the level of income, the lower the marginal utility. The term $\overline{W S}=\Sigma_{j} W_{j} s_{j} / N$ is the mean substitution effect of taxation on labor supply, which is also negative. The covariance term in (9), $\sigma_{Y a}^{2}=\frac{1}{N}\left[\Sigma_{j} W_{j} \frac{\partial H_{j}}{\partial t} W_{j} H_{j}-\left(\Sigma_{j} W_{j} \frac{\partial H_{j}}{\partial a}\right)\left(\frac{\Sigma_{j} W_{j} H_{j}}{N}\right)\right]$ shows the relationship between income and the income effect of taxation; it is non-negative when the effect of income on labor supply is small for those with high incomes.

The quantity $q_{j} \equiv \partial \tau_{j} / \partial t+\left(\partial \tau_{j} / \partial a\right) \bar{Y}$ in (9) is the change in the tax share of $j$ when the tax rate and the lump-sum transfer both change, where a bar above $Y$ denotes its mean. If we let $\psi_{j} \equiv V_{j \tau}^{*}=-\lambda_{j}^{*} P G_{j}^{*}$, we can write $\Sigma_{j} \lambda_{j}^{*} P G_{j}^{*}\left(\frac{\partial \tau_{j}}{\partial t}+\frac{\partial \tau_{j}}{\partial a} \bar{Y}\right)=\Sigma_{j} \psi_{j} q_{j}$. Using the covariance formula, the right side of this last expression is $\Sigma_{j} \psi_{j} q_{j}=N \sigma_{\psi q}^{2}+N \bar{\psi} \bar{q}$, where $\bar{\psi}$ and $\bar{q}$ denote the mean values of $\psi_{j}$ and $q_{j}$, respectively. Here $\sigma_{\psi q}^{2}$ captures the relationship between the marginal utility of the tax share and the marginal tax share and is an important 
determinant of how coercion is spread across the community. The value of $\sigma_{\psi q}^{2}$ depends on the size of the parameters of the utility function and is therefore an empirical matter. If taxpayers who experience a large increase in their tax shares will also experience a significant fall in utility, $\sigma_{\psi q}^{2}$ will be negative. In addition, by differentiating the tax share we obtain $\Sigma_{j} \partial \tau_{j} / \partial t=\Sigma_{j} \partial \tau_{j} / \partial a \bar{Y}=0$ and thus $\bar{q}=0 .{ }^{18}$

This last result and the definition of $\sigma_{\psi q}^{2}$ in (9) leads to the coercion-constrained optimal income tax rate:

$$
t=\frac{(1+\kappa) \sigma_{\lambda Y}^{2}+\kappa \sigma_{\psi q}^{2}}{\mu\left(\overline{W S}-\sigma_{\psi q}^{2}\right)}
$$

When the shadow price is positive and the $\sigma_{\psi q}^{2}$ covariance is negative, the optimal rate $t$ rises with $\kappa$ because the $\sigma_{\lambda Y}^{2}$ covariance is negative and so is the denominator. That is, the higher is the payoff to solidarity with the aims of the unconstrained social planner, the higher the optimal coercion-constrained income tax rate. However, note that the size of government and of tax rates may still be lower in the constrained situation than in the traditional social plan. ${ }^{19}$

By comparing equation (10) with its traditional counterpart, obtained by setting $\kappa=0$ (which need not be stated explicitly here), one can see that the more general formulation of the optimal tax rate features four new terms in comparison to the standard formula: the shadow price of coercion $\kappa$; the covariance $\sigma_{\psi q}^{2}$ between the marginal utility of the tax share and the marginal tax share; and via $\sigma_{\lambda Y}^{2}$, the translation of the tax system into tax shares $\partial \tau_{j} / \partial a$ and the translation of the tax price into welfare via the demand for $G, \lambda_{j}^{*} P G_{j}^{*}$.

The analogue to conditions (8) and (10) when individual coercion constraints are imposed on the planner is worked out in the Appendix. The solutions are much more complicated, involving also the distributional pattern of coercion as one should expect. It turns out to be the case that in comparison to the Kaldor-Hicks-like situation, government size and tax rates may be larger or smaller when coercion is specified at the individual level. 


\section{The Trade-off between Social Welfare and Coercion}

The existence of the trade-off in the present framework allows us to explore some of the implications for public finance of the clash of social objectives with individual rights embedded in the coercion constraints. We begin by considering the relationship of the shadow price of coercion and the degree of coercion in the case of the linear income tax and the welfare-coercion trade-off implied by this relationship. In the linear income tax case, maximization of social welfare subject to the government budget and an aggregate coercion constraint involves solving a system of five equations: first order conditions (1) - (3), the government budget constraint $t \sum_{j} W_{j} H_{j}=N a+P G$, and the coercion constraint $\Sigma_{j}\left(V_{j}^{*}-V_{j}\right)$ $=K$. The five unknowns are the three fiscal parameters, $t, a$, and $G$, and the two Lagrange multipliers, $\kappa$ and $\mu$. This means that the solution for the shadow price of coercion (along with the rest of the endogenous variables) is a function of the distribution of individual tastes for work, leisure, and consumption, captured by the parameters of the utility function and denoted by $\boldsymbol{\Gamma}$; the characteristics of the distribution of earning abilities captured by the wage rates and denoted by $\boldsymbol{W}$; the marginal cost of the public good $P$; and the level of coercion $K$.

We may write the implied solution for the shadow price of coercion (as well as that for all other endogenous variables) as $\kappa=\kappa(\boldsymbol{\Gamma}, \boldsymbol{W}, P, K)$, and the general solution for coercion-constrained social welfare as $S^{*}=F(\boldsymbol{\Gamma}, \boldsymbol{W}, P, K)$. As noted earlier, these are linked by the envelope theorem $d S * / d K \equiv \Sigma_{j}\left(d V_{j} / d K\right)=\kappa$. If $\kappa$ is positive (negative), coercionconstrained social welfare is rising (falling) with the level of coercion $K$, and when $\kappa$ is zero, social welfare is at its maximum and policy instruments will conform to their traditional optimal tax values. $k(\boldsymbol{\Gamma}, \boldsymbol{W}, P, K)=0$ thus defines implicitly the value of $k\left(K^{O T}\right)$ that is implied by traditional social planning.

Figure 3 illustrates one possible relationship between the shadow price and the aggregate degree of coercion. The part of the $\kappa-K$ curve labeled the "consensual society" is where welfare and coercion are positively correlated. This part is where any society that positively values both social welfare and the absence of coercion would like to be. Such a society would not want to be at the point associated with a traditional social plan, where $K=K^{O T}$. 
Figure 3: A Possible Relationship Between the Shadow Price of Coercion $\kappa$ and the Aggregate Degree of Coercion $K$

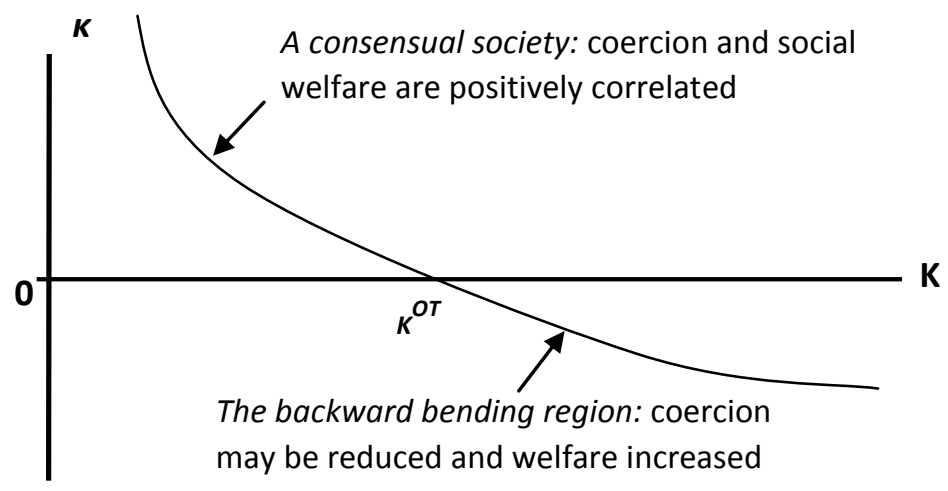

$\boldsymbol{K}^{O T}=$ the degree of aggregate coercion corresponding to the traditional (coercion -unconstrained) social plan

The part of the $\kappa-K$ curve to the right of $\mathrm{K}^{\mathrm{OT}}$ corresponds to the downward sloping part of the welfare-coercion trade-off, where welfare increases as coercion declines. This part is to be avoided without compensating virtues.

In the example illustrated, the implied trade-off between social welfare and coercion would be concave with its peak at $K^{O T}$. However, this is a hypothetical relationship. What does the welfare-coercion trade-off look like for the linear income tax case we have explored? This turns out to be a difficult question to answer. As shown in the Appendix, in the linear income tax model with an aggregate coercion constraint, we cannot even sign the slope of the shadow price - coercion relationship, the derivative $d \kappa / d K$, without further assumptions.

In the next section, we provide an explicit derivation of the trade-off between social welfare and the degree of coercion in a more simplified setting. Here we shall also compare the point on the trade-off chosen by a traditional social planner with the outcomes that result from the operation of exogenously determined collective choice processes.

\section{The Welfare-Coercion Trade-off in a Simplified Setting}

To proceed further, we assume that taxation is strictly proportional to income, utility is Cobb-Douglas, and aggregate coercion is measured using levels of the public good as in case 4 of Table 1 . The utility function of voter $j$ is defined over private consumption $X_{j}$ and a public good $G ; \quad U_{j}=\alpha_{j} \ln X_{j}+\gamma_{j} \ln G, \alpha_{j}+\gamma_{j}=1$. Income $Y_{j}$ is assumed to be 
exogenous, and there are $N$ individuals in the society. Because the tax system is proportional at rate $t$, for each citizen, $X_{j}=(1-t) Y_{j}$. Normalizing the unit price of the public good to unity, the budget constraint of the government is $t \sum_{j} Y_{j}=G$. Aggregate coercion will be defined by the level of the public good, so that the coercion constraint is

$$
K=\sum_{j}\left(G-G_{j}^{*}\right)^{2}, j=1, \ldots, N
$$

Because there are only two policy instruments linked by the government budget restraint in the simplified setting, the coercion constraint is sufficient to determine the level of the public good in the coercion-constrained planning problem once the counterfactual, $G_{j}^{*}$, is specified. The latter is determined by maximizing $U_{j}$ subject to the budget constraint $Y_{j}=X_{j}+\tau_{j} G_{j}$, where $\tau_{j}$ is the ratio of the tax paid by $j$ to the total tax revenue, $\tau_{j}=T_{j} / \sum_{j} T_{j}$. With a proportional income tax system, the latter is simply $\tau_{j}=Y_{j} / \sum_{j} Y_{j}$. Indirect utility of $j$ can then be written as $V_{j}=\left(1-\gamma_{j}\right) \ln \left(1-\left(\frac{G_{j}}{\Sigma_{j} Y_{j}}\right) Y_{j}\right)+\gamma_{j} \ln G_{j}, \quad$ and maximization of this with respect to $G_{j}$ yields

$$
G_{j}^{*}=\gamma_{j} \sum_{j} Y_{j}
$$

Thus in the simplified model, the counterfactual demand for the public good depends only on the individual taste for the good and total income and is independent of what the planner does. ${ }^{20}$

It will be helpful at this point to outline the outcome of coercion-unconstrained or traditional social planning, as a benchmark for what is to follow. This planner chooses $G$ and $t$ to maximize the weighted sum of individual utilities, $S=\sum_{j} z_{j} V_{j}, \sum_{j} z_{j}=1$, subject to the government budget restraint. (The introduction of the weights $z_{j}$ will facilitate later comparison of social planning with collective choice processes.) Using the covariance formula $\sum z \gamma=N\left(\sigma_{z \gamma}^{2}+\bar{z} \bar{\gamma}\right)$, where a bar denotes the mean value of a variable, and exploiting the equality $N \bar{z}=1$, maximization of welfare $S$ subject (only) to the government budget constraint yields the optimal policy: 


$$
G^{O T}=\left(\bar{\gamma}+N \sigma_{z \gamma}^{2}\right) \Sigma Y \text { and } t^{O T}=\bar{\gamma}+N \sigma_{z \gamma}^{2}
$$

The aggregate degree of coercion associated with this standard fiscal system is not zero. Using $G^{O T}$ in (11) shows that the degree of coercion in traditional social planning is positive and equal to

$$
K^{O T}=N(\Sigma Y)^{2}\left[\sigma_{\gamma}^{2}+\left(N \sigma_{z \gamma}^{2}\right)^{2}\right] .
$$

Intuitively, coercion in a social plan rises with the magnitude of demands for the public good, because the welfare losses from departures from preferred counterfactuals are larger then, with heterogeneity of tastes for the public good, because it is harder to satisfy a more heterogeneous community with the same restricted set of policy instruments, and with the covariance between the intensity of preferences for the public good and the weights of individuals in the social welfare function, because the social planner attaches a higher priority to the satisfaction of those with high preference for the public good. (When individuals with intense preference for the public good, high value of $\gamma$, enter the social welfare function with a large weight, high value of $z$, the covariance $\sigma_{z \gamma}^{2}$ is positive, and so $K^{O T}$ is rising with the latter.)

\subsection{The Trade-off}

Observing the coercion constraint generally requires that a nonlinear relationship be maintained between aggregate coercion and public sector size. Substituting from (12) into the coercion constraint (11) and using formulas for mean and variance indicates that

$$
\mathrm{K}=\mathrm{N}\left[\mathrm{G}^{2}-2 \bar{\gamma}(\Sigma \mathrm{Y}) \mathrm{G}+\left(\sigma_{\gamma}^{2}+\bar{\gamma}\right) \times(\Sigma \mathrm{Y})^{2}\right]
$$

where implicitly, $d G / d K=1 / 2 N(G-\bar{\gamma} \Sigma Y)$. Therefore, $G$ increases with $K$ as long as its initial size is greater than $\bar{\gamma} \Sigma Y$, the standard optimal tax value when $\sigma_{z \gamma}^{2}=0$, and it decreases with $K$ when $G$ is less than this value. This is a complicated pattern, showing the difficulty of making comparisons of the fiscal system in a coercion-constrained fiscal system and in a traditional social plan using general formulas like (8) and (10). 
To derive coercion-constrained social welfare, $S$, we substitute $G$ implicitly defined by (15) into the indirect utility functions in $S$ and aggregate across citizens. The result yields the welfare-coercion trade-off. Differentiating $S$ so derived with respect to $K$, we see that

$$
\begin{gathered}
\frac{d S}{d K}=\frac{G^{O T}-G}{2 N(G-\bar{\gamma} \Sigma Y)(\Sigma Y-G) G} \\
\frac{d^{2} S}{d K^{2}}=\frac{G\left(G-G^{O T}\right)\left[(1+\bar{\gamma}) \sum Y-2 G\right]+\left(\sum Y-G\right) G^{O T}\left(\bar{\gamma} \sum Y-G\right)}{4 N^{2} G^{2}\left(\sum Y-G\right)^{2}\left(G-\bar{\gamma} \sum Y\right)^{3}} .
\end{gathered}
$$

and

Then, using (13) and the definition of aggregate private consumption, $\sum_{j} X_{j}=\sum_{j} Y_{j}-G$, shows that ${ }^{21}$

$$
\frac{d S}{d K}=0 \quad \text { and } \quad \frac{d^{2} S}{d K^{2}}=\frac{-G^{O T}}{4 N^{4} G^{O T}(\Sigma X)\left(\sigma_{z \gamma}^{2}\right)^{2}}<0 .
$$

We can conclude that when the standard social plan is employed, welfare reaches its unconstrained maximum and that the trade-off between social welfare and the degree of coercion is globally concave. This concave trade-off is illustrated in Figure 4. The upward sloping part of the trade-off corresponds to what we referred to as the "consensual society" in Figure 3.

In Figure $4, K^{O T}$ is again the degree of coercion corresponding to social planning. $K^{M R}$ is the degree of coercion corresponding to majority rule in a competitive political system, which we shall analyze shortly. The origin $(K=0)$ is blanked out because the Lindahl solution may not be feasible, and if so, the planner's coercion-constrained social welfare planning problem is then not defined. 


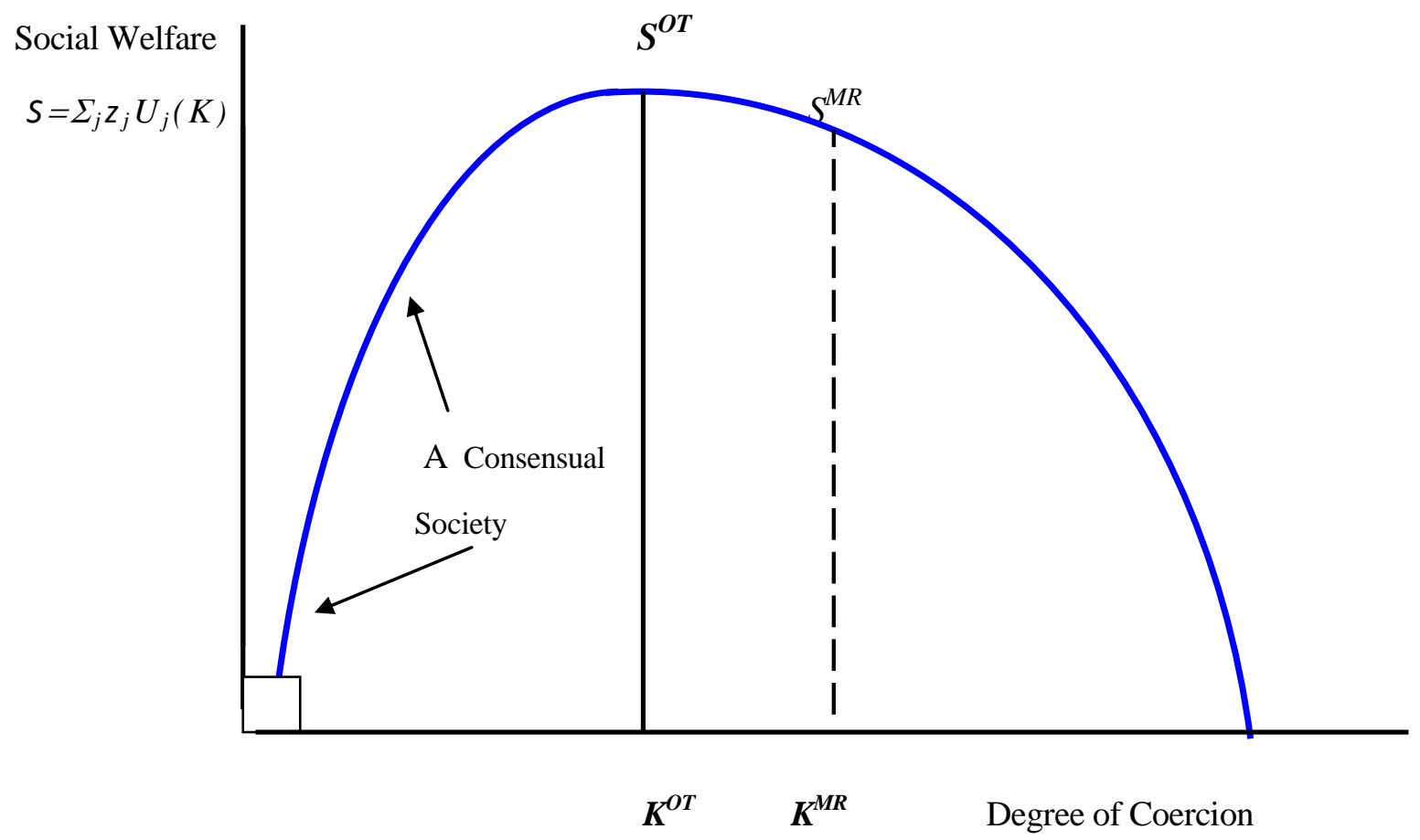

\section{Collective choice Versus Social Planning}

The use of coercion constraints represents a general approach of analysis that is also applicable in other settings of fiscal decision making, thus allowing for a new type of comparison among systems for reaching collective choices. To explore this important extension of the approach, we now inquire as to how democracy compares to the traditional social plan in terms of their implied trade-off between welfare and coercion. We shall consider a competitive electoral system in which policy outcomes represent a balancing of the heterogeneous economic interests of citizens, as in a probabilistic spatial voting model. This model is well described in the literature (see, for example, Hettich and Winer 1999, Persson and Tabellini 2000, Tridimas and Winer 2005, Adams, Merrill and grofman 2005, and Schofield and Sened 2006) and will be outlined quickly here. Variants of this model can be used to describe equilibria in proportional or majoritarian electoral systems, but we shall retain a more general viewpoint.

There are two expected vote-share-maximizing parties, A and B, whose policy platforms converge in the competitive political equilibrium. Voting behavior of individual citizens differs according to their economic interests including tastes for the public good, as 
well as according to individual political sensitivities, or propensities to switch support between parties if one of them offers the voter a more preferred fiscal system. Parties are assumed to have the same knowledge of the stochastic distribution of the characteristics of voters.

Whether a voter votes for party A depends on two components: a policy component and a non-policy component. The policy component depends on the indirect utility of the voter (specified earlier) when party A rather than B implements its proposed policy. The nonpolicy component, or valence, depends on how the voter evaluates the ideology or other personal characteristics of the competing politicians. ${ }^{22}$ Formally, voter $j$ supports party $\mathrm{A}$ if $V_{j}\left(G_{A}, t_{A}\right)>V_{j}\left(G_{B}, t_{B}\right)+\rho+s_{j}$, where $V$ is again indirect utility. The valence term $\left(\rho+s_{j}\right)$ has two components: $\rho$ common to all voters and uniformly distributed on $[-1 / 2 \xi, 1 / 2 \xi]$, and a term $s_{j}$, which is an idiosyncratic preference uniformly distributed on $\left[-\left(\frac{1}{2}\right) \zeta_{j}+\right.$ $\left.h_{j},\left(\frac{1}{2}\right) \zeta_{j}+h_{j}\right]$.

The expected vote share that party A maximizes by choice of a fiscal system is

$$
P_{A}=\frac{\xi}{\zeta_{j}} \Sigma_{j}\left\{\zeta_{j}\left[V_{j}\left(G_{A}, t_{A}\right)-V_{j}\left(G_{B}, t_{B}\right)\right]\right\}+\frac{1}{2} \frac{\xi}{\sum_{j} \zeta_{j}}
$$

Here, $\zeta_{j}$ represents the voter's political sensitivity - that is, the effect on the probability that he will support party A of a change in his well-being (that results from a proposed change in A's platform.) Analogously, B maximizes $P_{B}=1-P_{A}$.

Because the parties converge in the Nash electoral equilibrium, to characterize the equilibrium without loss of generality we maximize $P_{A}$ with respect to $G_{A}$ and $t_{A}$ subject to the budget constraint facing any successful party, with $G_{B}$ and $t_{B}$ constant, which requires

$$
\frac{d P_{A}}{d G}=\sum_{j} \zeta_{j} \frac{d V_{j}}{d G}=0 .
$$

Since utility is Cobb-Douglas, this implies that the political equilibrium values of $G$ and $t$ are

$$
G^{M R}=\frac{\sum_{j} \zeta_{j} \gamma_{j}}{\sum_{j} \zeta_{j}} \Sigma_{j} Y j \quad \text { and } \quad t^{M R}=\frac{\Sigma_{j} \zeta_{j} \gamma_{j}}{\sum_{j} \zeta_{j}}
$$


Denoting the relative political sensitivity of voters $j$ by $\theta_{j} \equiv \zeta_{j} / \sum_{j} \zeta_{j}, \Sigma \theta_{j}=1$ and using the covariance formula, equilibrium fiscal structure can then be written in a convenient form easily compared to the policy (13) chosen by the unconstrained planner:

$$
G^{M R}=\left(\bar{\gamma}+N \sigma_{\theta \gamma}^{2}\right) \Sigma Y \text { and } t^{M R}=\bar{\gamma}+N \sigma_{\theta \gamma}^{2}
$$

The corresponding degree of coercion is

$$
K^{M R}=N(\Sigma \mathrm{Y})^{2}\left[\sigma_{\gamma}^{2}+\left(N \sigma_{\theta_{\gamma}}^{2}\right)^{2}\right]
$$

That is, similarly to (14), the degree of coercion will be higher with the size of demands for the public good (captured by the level of income), the heterogeneity of tastes for the public good (captured by $\sigma_{\gamma}^{2}$ ), and the covariance between the intensity of preferences for the public good and the political sensitivity of voters $\left(\sigma_{\theta \gamma}^{2}\right)$, because voters with high intensity of preference for the public good are politically more influential.

A comparison of planning and democratic political competition shows that

$$
K^{M R}-K^{O T}=N^{3}\left[\left(\sigma_{\theta \gamma}^{2}\right)^{2}-\left(\sigma_{z \gamma}^{2}\right)^{2}\right](\Sigma \mathrm{Y})^{2} .
$$

If the planner weighs all citizens equally $\left(\sigma_{z \gamma}^{2}=0\right)$, coercion in the competitive political system will always exceed that imposed by the social planner. The essential reason for this is that majority rule introduces fiscal discrimination according to political influence, in addition to that according to narrowly defined individual economic preferences. And, because $K^{O T}$ corresponds to the point of maximum welfare, social welfare in the democracy will be lower, at some point on the backward bending part of the trade-off.

One possibility that this conclusion opens up is that of reducing coercion while raising social welfare, either by imposing additional constraints on the nature of fiscal instruments (as Simons (1938) and Buchanan and Congleton (1998) suggest) or by changing the nature of the collective choice mechanism (as suggested by Wicksell (1896) and many others since). ${ }^{23}$ Another possibility is that the constraints on state action imposed by globalization may serve as effective constraints on coercion. However, exactly what each 
proposed or actual institutional change implies in terms of a well-defined welfare-coercion trade-off remains to be formally investigated in future research.

\section{Conclusion}

Although coercion is a central fact in the design and operation of the public sector, normative public economics based on the planning model has not made it an explicit element of the analysis. In this essay, we formally introduce coercion into normative analysis by adding constraints that limit allowable coercion caused by tax and expenditure programs. We focus on situations that arise when citizens experience a mismatch between what they receive in public goods and services and what they pay in taxes. The essay demonstrates that it is possible to conduct formal analysis of the structure of public policy taking coercion into account even without knowing the optimal degree of coercion. In particular, one can delineate the welfare-coercion trade-off and ask what policies are consistent with attainment of the frontier and where particular institutions lead in relation to coercion-unconstrained social planning.

To make the concept of coercion operational, a counterfactual specifying what individuals regard as appropriate treatment by the public sector is required. We have employed a counterfactual that assumes that the individual accepts some coercion by society, along with a socially determined tax price. One may then specify coercion constraints either in terms of individual or aggregate utility or by using a convenient approximation that relies on a reference level of government expenditure. The aggregate definitions are analogous to the use of the Kaldor-Hicks-Scitovsky criterion and impose a less severe constraint on decision making than those having an individual basis.

Coercion constraints have important and complex effects on a social plan. Using both

aggregate (KHS-like) and individual coercion constraints, we work out these effects for a fiscal system that uses an optimal linear income tax to provide a public good. These cases were chosen because they permit straightforward comparisons with standard optimal tax results, including the size of government, the pattern of average rate progressivity, and the marginal cost of funds. A novel aspect of the analysis relates to the trade-off between social welfare as traditionally defined and coercion. Using a Cobb-Douglas formulation, we derive a trade-off function, as well as the degree of coercion implied by unconstrained social planning. The analysis allows us to examine how to achieve the highest level of traditionally 
defined welfare for a given degree of coercion or, in other words, how to be coercion efficient. The trade-off between narrowly defined welfare and aggregate coercion raises the possibility that collective choice in a democracy will tend to lead us to a point on the downward sloping part of the trade-off, opening up the possibility that coercion may be reduced and social welfare increased by appropriate institutional reform.

Extensions of the analysis are possible in several directions. One could, for example, explicitly account for the interaction of incentive compatibility and coercion constraints. Such interaction would occur in situations in which the coercion of individuals in different income groups is relevant to decision making by those who may find it advantageous to mimic the behavior of others. In addition, coercion will have relevance for the structure of the fiscal system. Although we have considered coercion when only an income tax is employed, the analysis could be extended to situations in which a full mix of direct and indirect taxes exists. ${ }^{24}$ More generally, the relationship between complexity of tax structures and the coercion-welfare trade-off also deserves investigation. One suspects that more complex fiscal systems, which are also administratively more costly, may involve less coercion for a given level of welfare. ${ }^{25}$

The trade-off analysis can also be used to investigate how coercion can be reduced at

given levels of social welfare through institutional means. Work on the scope of the public sector suggests that the boundary between private and public sectors matters in this regard and that the welfare-coercion frontier may be shifted favorably by removing certain types of economic activity from the public sphere. The trade-off function could be used to formalize this argument.

Public goods coercion also has relevance for the discussion of federalism. Following Tiebout (1956), the literature on optimal assignment in federations has been concerned with balancing the welfare gains from decentralization with the loss of efficiency from fiscal externalities that arise under decentralized decision making. One may expect decentralization to reduce coercion, but this connection has not yet been formally acknowledged or analyzed in the optimal assignment literature. ${ }^{26}$

Finally, the welfare-coercion frontier also allows us to extend the analysis of collective choice in an important way. The concept provides a new basis for comparing 
political equilibria under alternative institutional arrangements or voting rules and for the ranking of such equilibria with respect to the implied trade-off between welfare and coercion.

\section{References}

Acemoglu, Daron, Michael Golosov and Aleh Tsyvinski (2008). "Dynamic Mirrlees Taxation under Political Economy Constraints.” Working paper 08-08, February 15. Cambridge, MA: MIT.

Acemoglu, Daron and James A. Robinson (2013). "Economics versus Politics: Pitfalls of Policy Advice." Journal of Economic Perspectives 27(2): 173-192.

Adams, J. F., S. Merrill III and B. Grofman. (2005). A Unified Theory of Party Competition. A CrossNational Analysis Integrating Spatial and Behavioural Factors. NewYork: Cambridge University Press.

Alesina, Alberto and Enrico Spolaore (2003). The Size of Nation. Cambridge, MA: MIT Press.

Alm, James, Gary H. McClelland and William D. Schulze (1992). "Why Do People Pay Taxes?" Journal of Public Economics 48(1): 21-38.

Anderson, Scott (2006). "Coercion. Stanford Encyclopedia of Philosophy." http://plato.stanford.edu/entries/coercion.

Atkinson,AnthonyB. andNicholasH. Stern(1974). "Pigou,Taxation andPublicGoods." Review of Economic Studies 41: 119-128.

Atkinson, Anthony B. and Joseph E. Stiglitz (1980). Lectures on Public Economics. New York: McGraw-Hill.

Becker, Gary (1983). "A Theory of Competition among Pressure Groups for Political Influence." Quarterly Journal of Economics 98: 371-400.

Boadway, Robin (2002). "The Role of the Public Choice Considerations in Normative Public Economics." In Stanley L.Winer andHirofumi Shibata (eds.),Political Economy and Public Finance. Cheltenham: Edward Elgar, 47-68.

Boadway, Robin and Maurice Marchand (1995). "The Use of Public Expenditures for Redistributive Purposes." Oxford Economic Papers, New Series, 47(1): 45-59.

Breton, Albert (1974). The Economic Theory of Representative Government. Chicago: Aldine.

Breton, Albert (1996). Competitive Governments: An Economic Theory of Politics and Public Finance. Cambridge: Cambridge University Press.

Buchanan, James M. (1964). "Fiscal Institutions and Efficiency in Collective Outlay." American Economic Review, Papers and Proceedings 54(May): 227-235.

Buchanan, James M. (1968). The Demand and Supply of Public Goods: Chicago. Chicago: Rand McNally.

Buchanan, James M. and Roger Congleton (1998). Politics by Principle, Not Interest. New York: Cambridge University Press.

Buchanan, James M. and Gordon Tullock (1962). The Calculus of Consent. Logical Foundations of Constitutional Democracy. Ann Arbor: University of Michigan Press.

Clower, Robert (1967). "A Reconsideration of the Microfoundations of Monetary Theory." Western Economic Journal 6: 1-8.

Dalton, Thomas (1977). "Citizen Ignorance and Political Activity." Public Choice 32: 85-99.

Escarrez, D. R. (1967). "Wicksell and Lindahl: Theories of Public Expenditure and Tax Justice Reconsidered." National Tax Journal 20: 137-148.

Gordon, Scott (1999). Controlling the State: Constitutionalism from Ancient Athens toToday. Cambridge, MA: Harvard University Press.

Hart, H. L. A. (1961). The Concept of Law. Oxford: Oxford University Press.

Hettich, Walter and Stanley L. Winer (1985). "Blueprints and Pathways: The Shifting Foundations of Tax Reform." National Tax Journal 38(4): 423-445.

Hettich, Walter and Stanley L. Winer (1988). "Economic and Political Foundations of Tax Structure." American Economic Review 78(4): 701-712.

Hettich, Walter and Stanley L. Winer (1999). Democratic Choice and Taxation: A Theoretical and Empirical Investigation. Cambridge, MA: Cambridge University Press. 
Hirschman, Albert O. (1970). Exit, Voice and Loyalty: Responses to Declines in Firms, Organizations and States. Cambridge, MA: Harvard University Press.

Kaplow, Louis (2008). Pareto Principle and Competing Principles, in Steven Durlauf and Laurence E. Blum (eds.), The New Palgrave Dictionary of Economics, 2nd Edition, Vol. 6. Basingstoke: Palgrave Macmillan, 295-300.

Leiser, B. M. (2008). "On Coercion.” In D. Reidy and W. Riker (eds.), Coercion and the State. Berlin: Springer, 31-43.

Levy, Margaret (1997). Consent, Dissent, and Patriotism. Cambridge, MA: Cambridge University Press.

Lindahl, Eric (1919/1958). "Just Taxation.APositive Solution." In RichardMusgrave and Alan Peacock, Classics in the Theory of Public Finance. London: Macmillan, 168-176.

Mirrlees, James A. (1971). "An Exploration in the Theory of Optimum Income Taxation." Review of Economic Studies 38: 175-208.

Mueller, Dennis (2003). Public Choice III. New York: Cambridge University Press. Patinkin, Don (1965). Money, Interest and Prices: An Integration of Monetary and Value Theory, 2nd edition. New York: Harper and Row.

Pennock, Roland (1959). "Federal and Unitary Government - Disharmony and Frustration." Behavioral Science 4: 147-157.

Perroni, Carlo and Kimberley Scharf (2003). "Viable Tax Constitutions." CEPRWorking Paper DP 4210. University ofWarwick.

Persson, Torsten and Guido, Tabellini (2000). Political Economics, Explaining Economic Policy. Cambridge MA: MIT Press.

Ramsey, Frank P. (1927). "A Contribution to the Theory of Taxation.” Economic Journal 37: 47-61.

Reidy, DavidA. andWalter J. Riker (eds.) (2008). Coercion and the State. Berlin: Springer.

Riker, William H. (1982). Liberalism Against Populism: A Confrontation Between the Theory of Democracy and the Theory of Social Choice. San Francisco:W.H. Freeman \& Company.

Sandmo, Agnar (1998). "Redistribution and theMarginal Cost of Public Funds." Journal of Public Economics 70: 365-382.

Schofield, N., and Itai Sened (2006). Multiparty Democracy: Parties, Elections and Legislative Politics in Multiparty Systems. New York: Cambridge University Press.

Simons,Henry C. (1938). Personal IncomeTaxation:TheDefinition of Income as a Problem of Fiscal Policy. Chicago: University of Chicago Press.

Skaperdas, Stergios (1992). "Cooperation, Conflict, and Power in the Absence of PropertyRights." American Economic Review 82: 720-739.

Tiebout, Charles (1956). "A Pure Theory of Local Expenditures.” Journal of Political Economy 64: $416-424$.

Tridimas, George and Stanley L. Wine (2005). "The Political Economy of Government Size." European Journal of Political Economy 21: 643-666.

Usher, Dan (1993). TheWelfare Economics ofMarkets, Voting and Predation. AnnArbor: University of Michigan Press.

Wicksell, Knut (1896/1958). “A New Principle of Just Taxation.” In R. Musgrave and A. Peacock, Classics in the Theory of Public Finance. London: Macmillan, 72-118.

Wildasin, David (2006). "Fiscal Competition.” In Barry R. Weingast and Donald A.

Wittman (eds.), The OxfordHandbook of Political Economy. Oxford:OxfordUniversity Press 502520.

Wilson, John (1999). “Theories of Tax Competition.” National Tax Journal 52: 269-304.

Wiseman, Jack (1989). Cost, Choice and Political Economy. Cheltenham: Edward Elgar.

Yitzhaki, Shlomo (1979). "A Note on Optimum Taxation and Administrative Costs." American Economic Review 69: 475-480. 


\section{Appendix}

1. Linear Income Taxation with Individual Coercion Constraints

When the planner is constrained by how much he or she can coerce each individual taxpayer separately (as in case 1 of Table 1), the Lagrangean for the planning problem becomes

$$
L=\Sigma_{j} V_{j}+\mu\left[t \Sigma_{j} W_{j} \mathrm{H}_{j}-N a-\mathrm{P} G\right]+\Sigma_{j} \kappa_{j}\left[K_{j}-\left(V_{j}^{*}-V_{j}\right)\right]
$$

Although the situation is considerably more complex than before, the corresponding first order conditions are generalizations of equations (7) and are not stated here. Working as before, the condition for the optimal coercion-constrained size of government (analogous to condition (8)) becomes $^{27}$

$$
\left(\sum_{j} m_{j}\right)[(1+\delta)(1+\kappa)+\kappa \phi]=\frac{\mu}{\lambda}\left(P-t \Sigma_{j} W_{j} \frac{\partial H_{j}}{\partial G}\right)
$$

where in addition to previous definitions, $s_{\kappa \lambda}=\sigma^{2}{ }_{\kappa \lambda} / \lambda \kappa$ is the covariance between coercion and the marginal utility of income; $s_{\kappa m}=\sigma_{\kappa m}^{2} / \kappa m$ is the covariance between coercion and the

marginal rate of substitution; $s_{\kappa \lambda m}=\sigma_{\kappa \lambda m}^{2} / \kappa \lambda m$ is the covariance between coercion, the marginal utility of income, and the marginal rate of substitution; and finally, where $\phi \equiv s_{\kappa \lambda}+$ $s_{\kappa m}+s_{\kappa \lambda m}$

The right-hand side of equation (A2) is already familiar. It is the product of the marginal valuation of government revenue times the net marginal rate of transformation of the public good. The left-hand side of (A2) again shows the marginal benefit from the public good. However, now it is the product of the sum of marginal rates of substitution multiplied by the adjustment for the combined effect of the distributional characteristics of the public good and the effects of coercion. In the present case of individual coercion constraints, the adjustment for coercion contains two new elements relative to standard social planning, (a) the average effect of coercion $(1+\delta)(1+\kappa)$, a term that also appears in the previous case of aggregate coercion, and (b) the term $\kappa \phi$, which corrects the aggregate term for the "distributional characteristics of coercion." 
We use the term "the distributional characteristics of coercion" advisedly here, for want of a better one. Because concern with coercion arises out of concern with individual rights or, alternatively, with the degree of social solidarity individuals have with the objectives of the planner, it is not clear that we ought to think about it the same way that we do redistribution in the traditional planning model.

Now the benefit from public provision increases in the following cases, assuming $\kappa$ is positive: (a) if the rich (low $\lambda_{j}$ ) view the payoff from solidarity with the planner less favorably (low $\kappa$ ), so that $\sigma_{\kappa \lambda}^{2}>0$ and $s_{\kappa \lambda}>0$; (b) if those who value public goods less (low $m_{j}$ ) "have less social solidarity" (low $\kappa$ ), then $\sigma_{\kappa m}^{2}>0$ and $s_{\kappa m}>0$; and (c) if the rich (low $\lambda_{j}$ ) also value public goods less (low $m_{j}$ ), so that $\sigma_{\kappa \lambda m}^{2}>0$ and $s_{\kappa \lambda m}>0$, because the previous two effects are compounded.

If all these conditions apply, $\phi$ is positive. Then, on comparing (8) and (A2), one can also say that the KHS-like solution for a coercion-constrained optimum (8) will involve less spending and a lower tax rate than when coercion is defined on an individual basis. However, either of these comparisons could in principle go the other way, and it will be interesting to determine in practice what situation is likely to apply.

To derive the optimal income tax rate under individual coercion constraints, we require additional covariances (normalized again by the means of the indicated variables): $\sigma_{\kappa \lambda Y}^{2}=$ the covariance of $\kappa_{j}, \lambda_{j}$ and $Y_{j} ; \quad \sigma_{\kappa \psi q}^{2}=$ the covariance of $\kappa_{j}, \psi_{j}$, and $q_{j} ; \sigma_{\kappa Y}^{2}=$ the covariance of $\kappa_{j}$ and $Y_{j} ; \sigma_{\psi q}^{2}=$ the covariance of $\psi_{j}$ and $\kappa_{j} ; \sigma_{\kappa q}^{2}=$ the covariance of $\kappa_{j}$; and $q_{j}$. Also, let $\kappa, \lambda, \psi$, and $q$ be the mean values of $\kappa_{j}, \lambda_{j}, \psi_{j}$, and $q_{j}$, respectively. Then, using these definitions and the Slutsky equation, and working as before, we obtain the formula for the coercion-constrained optimal income tax rate $^{28}$ :

$$
\mathrm{t}=\frac{(1+\kappa) \sigma_{\lambda Y}^{2}+\kappa \sigma_{\psi q}{ }^{2}+\lambda \sigma_{\kappa Y}^{2}+\psi \sigma_{\kappa q}^{2}+\sigma_{\kappa \lambda Y}^{2}+\sigma_{\kappa \psi q}^{2}}{\mu\left(\overline{W S}-\sigma_{Y a^{2}}\right)}
$$

This optimal income tax rate depends as usual on the income distribution effect of taxation, captured by $\sigma_{\lambda Y}^{2}$, and the efficiency effect of taxation on labor (shown again by the denominator). In common with the case of aggregate coercion, it also depends on the relationship between the marginal utility of the tax share and the marginal tax share $\sigma_{\psi \mathrm{q}}^{2}$. In addition, the optimal tax rate depends on the distributional effects of coercion, as the 
remaining four covariance terms make clear. It should be noted that little is presently known about the sign or size of the covariances involved.

\section{Derivation of $d \kappa / d K$ in Section 4, Showing that in the Case of Linear Income Taxation and an Aggregate Coercion Constraint, the Sign of This Derivative is Ambiguous}

Maximization of the welfare function subject to the government budget and the coercion constraint generate a system of five equations with five unknowns: the three first order conditions (1), (2), and (3), the government budget restraint (5), and the aggregate coercion constraint $\sum_{j}\left(V_{j}^{*}-V_{j}\right)=K$.

Here there are five unknowns: the three fiscal parameters, $t, a$, and $G$, and the two Lagrange multipliers, $\mu$ (for the budget constraint) and $\kappa$ (for the coercion constraint). Solving the preceding system gives us the formulas for, $t, a$, and $G$ that we discuss in the text, as well as the solutions for $\mu$ and $\kappa$.

As noted in the text, the equilibrium values of the endogenous variables are a function of the distribution of individual tastes for work, leisure, and consumption, captured by the parameters of the utility function and denoted by $\Gamma$; the characteristics of the distribution of earning abilities captured by the wage rates and denoted by $\boldsymbol{W}$; the price of the public good $P$; and the degree of (aggregate) coercion $K$. We may write the system of reduced-form equations:

$t=t(\Gamma, W, P, K) ; a=a(\Gamma, W, P, K) ; G=G(\Gamma, W, P, K) ; \kappa=\kappa(\Gamma, W, P, K) ; \mu=\mu(\Gamma, W, P, K)$.

Using the assumptions of the linear tax model in Section 4, totally differentiating the system of equations (A4), using subscripts to denote derivatives and rearranging gives the following:

$$
\left[\begin{array}{ccccc}
A_{t t} & A_{t a} & A_{t G} & -\alpha_{t \mu} & \alpha_{t \kappa} \\
B_{a t} & B_{a a} & B_{a G} & -\beta_{a \mu} & \beta_{a \kappa} \\
C_{G t} & C_{a t} & C_{G G} & -\gamma_{G \mu} & \gamma_{G \kappa} \\
\alpha_{t \mu} & -\beta_{a \mu} & -\gamma_{G \mu} & 0 & 0 \\
\alpha_{t \kappa} & -\beta_{a \kappa} & -\gamma_{G \kappa} & 0 & 0
\end{array}\right] \times\left[\begin{array}{c}
d t \\
d a \\
d G \\
d \mu \\
d \kappa
\end{array}\right]=\left[\begin{array}{c}
0 \\
\mu d N \\
\mu d P+a d N \\
G d P \\
d K
\end{array}\right]
$$

where: 


$$
\begin{aligned}
& A_{t t} \equiv(1+\kappa) \Sigma\left(\lambda_{t} Y+\lambda Y_{t}\right)-\mu\left(2 \Sigma Y_{t}+t \Sigma Y_{t t}\right)-\kappa \Sigma \lambda * P G^{*} \tau_{t t} ; \\
& A_{t a} \equiv(1+\kappa) \Sigma\left(\lambda_{a} Y+\lambda Y_{a}\right)-\mu\left(\Sigma Y_{a}+t \Sigma Y_{t a}\right)-\kappa \Sigma \lambda * P G^{*} \tau_{t a} ; \\
& A_{t G} \equiv(1+\kappa) \Sigma\left(\lambda_{G} Y+\lambda Y_{G}\right)-\mu\left(\Sigma Y_{G}+t \Sigma Y_{t G}\right) ; \quad \alpha_{t \mu} \equiv \Sigma Y+t \Sigma Y_{t} ; \quad \alpha_{t \kappa} \equiv \Sigma \lambda Y-\Sigma \lambda * P G^{*} \tau_{t} \\
& B_{a t} \equiv(1+\kappa) \Sigma \lambda_{t}+\mu\left(\Sigma Y_{a}+t \Sigma Y_{a t}\right)+\kappa \Sigma \lambda * P G^{*} \tau_{a t} ; \\
& B_{a a} \equiv(1+\kappa) \Sigma \lambda_{a}+\mu t \Sigma Y_{a a}+\kappa \Sigma \lambda * P G^{*} \tau_{a a} ; \\
& B_{a G} \equiv(1+\kappa) \Sigma \lambda_{G}+\mu \Sigma Y_{a G} ; \quad \beta_{a \mu} \equiv N-t \Sigma Y_{a t} ; \quad \beta_{a \kappa} \equiv \Sigma \lambda+\Sigma \lambda * P G^{*} \tau_{a} \\
& C_{G t} \equiv(1+\kappa) \Sigma U_{G t}+\mu\left(\Sigma Y_{G}+t \Sigma Y_{G t}\right) ; \quad C_{G a} \equiv(1+\kappa) \Sigma U_{G a}+\mu t \Sigma Y_{G a} ; \\
& C_{G G} \equiv(1+\kappa) \Sigma U_{G G}+\mu t \Sigma Y_{G G} ; \quad \gamma_{G \mu} \equiv P-t \Sigma Y_{G} ; \quad \gamma_{G \kappa} \equiv \Sigma U_{G}
\end{aligned}
$$

By Cramer's rule, $\frac{d \kappa}{d K}=\frac{|D|}{|\Omega|}$ where $|\mathrm{D}|=\left|\begin{array}{cccc}A_{t t} & A_{t a} & A_{t G} & -\alpha_{t \mu} \\ B_{a t} & B_{a a} & B_{a G} & -\beta_{a \mu} \\ C_{G t} & C_{G a} & C_{G G} & -\gamma_{G \mu} \\ \alpha_{t \mu} & -\beta_{a \mu} & -\gamma_{G \mu} & 0\end{array}\right|$ and $|\Omega|$ is the determinant of the matrix of coefficients in (A5). This derivative cannot be signed unambiguously even with the assumptions of the simple linear income tax model, because none of the individual terms in the determinants of $\mathrm{D}$ and $\Omega$ can be signed without making further assumptions.

\section{Footnotes}

${ }^{1}$ If Lindahl pricing was feasible and implemented, at given tax prices everyone would vote for the same setting on the thermostat (or level of the public good). Disagreement over the setting of tax prices may remain however.

${ }^{2}$ See also Hirschman (1970), Skaperdas (1992), Usher (1993) and Alesina and Spolaore (2003).

${ }^{3}$ They argue that optimal policy then requires the distortionary taxation of both capital and labor to reduce the amount of rents that need to be paid to the politician. One may note here that incentive compatibility constraints are themselves dependent on the nature of threats and force that is permitted in society, an issue taken up by the editors in their introductory essay. They are not given entirely by the state of nature. What is known about individual politicians or taxpayers depends on the range of actions that may be legitimately applied in uncovering individual characteristics and in preventing socially undesirable behavior. See also Acemoglu and Robinson (2013) who argue for 
generally taking conflicts between economic and political forces into account in the design of public policy.

${ }^{4}$ Buchanan $(1968,145-146)$ stresses the importance of the nature of the social situation in doing public finance.

${ }^{5}$ Hart (1961) argues, as we see it, that to accept coercion as a result of a collective choice process, the individual must be assured that law-abiding citizens in society will not be taken advantage of. Or, in other words, that the situation must involve the threat of legal sanction backed by force to deal with possible tax evasion. The individual-in-society definition of coercion we shall use and that in the legal tradition may thus be seen as having a common basis. On coercion in the legal tradition, see also Anderson (2006)..

${ }^{6}$ Breton (1974) defines coercion as depending on the deviation of marginal evaluations of public services from tax prices. Although the total amount of coercion defined in (1) varies with this difference, it is not coercion itself.

${ }^{7}$ With a proportional tax (a linear income tax with no lump sum component), the point $(t, G)$ must lie on the dotted tax-share line. With a demogrant, the relationship between the tax rate and the individual tax share is more complicated.

${ }^{8}$ In an interesting paper complementary to the current one - the perspective is that of the first issue identified earlier - Perroni and Scharf (2003) develop a positive theory of the self-enforcing fiscal system. The problem they begin with is that there is no external power to enforce the power to tax so that ultimately, in their view, all fiscal systems must be self-enforcing equilibria in which the continual consent of the public is sought. They search for efficient, self-enforcing equilibria that are robust to renegotiation among groups of citizens. As a consequence, they claim (result 4) that when citizens have identical preferences, efficiency and renegotiation proofness requires horizontal equity in taxation. However, as they explicitly state, this is "fully unrelated to any distributional goal" (p. 9). Rather, in their approach, it is a matter of ensuring the stability and viability of society as a whole.

9 "From the point of view of general solidarity ... parties and social classes should ... share an expense from which they receive no great or direct benefit. Give and take is a firm foundation of lasting friendship. ... It is quite a different matter, however, to be forced so to contribute" Wicksell $(1896 / 1958,90)$.

${ }^{10}$ The same is true if coercion is put into the welfare function but outside of individual utilities.

${ }^{11}$ See Kaplow (2008) for an extensive comparison of the Pareto principle and criteria that formally depart from standard social welfare maximization, but which may nonetheless serve welfarist ends.

${ }^{12}$ It should be noted that it may be the case that only one of these two types of individuals will arise in a fiscal system. The reason is that coercion depends on what individuals think is appropriate treatment for themselves, not what is actually feasible for society as a whole.

${ }^{13}$ For example, we do not explicitly allow the planner to force independent evaluations of ability on taxpayers, or to coercively uncover economic activity, thereby relaxing incentive compatibility constraints.

${ }^{14}$ Here neither the tax rate $t$ nor the lump sum component $a$ varies across individuals, thus providing a simple way of introducing the excess burden of taxation while also ruling out a Lindahl voluntary exchange equilibrium in which taxes are raised without any welfare loss. With $a=0$ the tax is proportional to income, with $a>0$ it is progressive, and with a $<0$ regressive. For comparability with the literature, we follow Sandmo's (1968) notation.

${ }^{15}$ To help the reader follow later derivations, we note here that solving this problem yields the usual condition $U_{j L} / U_{j X}=(1-t) W_{j}$, the final demand for the private good $X_{j}=X_{j}\left[(1-t) W_{j}, a, G\right]$, the labor supply $H_{j}=H_{j}\left[(1-t) W_{j}, a, G\right]$, and the indirect utility function $V_{j}=V_{j}\left[(1-t) W_{j}, a, G\right]$. Denoting the marginal utility of income by $\lambda_{j}$, the partial derivatives of utility with respect to the fiscal variables for person $j$ are $V_{j t}=-\lambda_{j} Y_{j,}$ with $Y_{j}=W_{j}\left(1-L_{j}\right) ; V_{j a}=\lambda_{j}$ and $V_{j G}=U_{j G}$, and the marginal willingness to pay for the public good is $m_{j}=U_{j G} / U_{j X}=V_{j G} \lambda_{j}$.

${ }^{16}$ One may also note that if there is only one person, or if everyone is identical, there will be no difference between $V^{*}$ and $V$ at an optimum, and any coercion constraint will be irrelevant. Coercion as defined here has no meaning in a single agent planning model. 
${ }^{17}$ It is equal to the product of the marginal valuation of government revenue, $\mu / \lambda$ and the net (of induced revenue) rate of transformation of the public good, $P-t \sum_{j} W_{j}\left(\partial H_{j} / \partial G\right)$.

${ }^{18}$ To derive this expression, we differentiate $\tau_{j}$ in (3) with respect to $t$ and $a$ and recognize that a change in $t$ and $a$ affects the level of income.

${ }^{19}$ If the individual-as-dictator counterfactual had been used to define coercion, the counterfactual utility would no longer depend on the choice of the fiscal system, and the resulting formula for the tax rate would be simpler, omitting the second term in the numerator of (10). (The general form of the solution for $G$ given by equation (8) is the same with both counterfactuals, although the level of $G$ will differ in each case.)

${ }^{20}$ Thus the assumptions of Cobb-Douglas utility, defined over two goods only (with no labor- leisure choice), and exogenous income result in the same counterfactual level of $G^{*}{ }_{j}$ under both the individual-in-society and the individual-as-dictator approaches.

21 PROOF. Differentiation of $S(K)$ yields $d S / d K=\Sigma z(1-\gamma)[-1 /(\Sigma Y-G)] d G / d K+\Sigma z \gamma(1 / G) d G / d K$. Substituting from (15) we have $d S / d K=(\Sigma z \gamma \Sigma Y-\Sigma z G) / 2 N(G-\bar{\gamma} \Sigma Y)(\Sigma Y-G) G$. Recalling that $G^{O T}=$ $\sum z \gamma \Sigma Y$ and using the covariance formula yields the first derivative in (16). Differentiating this with respect to $K$, we obtain the following expression for the numerator of the second derivative in (16): [numerator $\left.\quad d^{2} S / d K^{2}\right]$
$\left[-(d G / d K)\left(-G^{3}+\Sigma Y(1+\bar{\gamma}) G^{2}-(\Sigma Y)^{2} \bar{\gamma} G\right)-(d G / d K)\left(-3 G^{2}+2 \Sigma Y(1+\bar{\gamma}) G-(\Sigma Y)^{2} \bar{\gamma}\right)(\Sigma Y \Sigma z \gamma-G)\right]$. Substituting for $d G / d K$ and rearranging then yields the second derivative, $Q E D$.

${ }^{22}$ Adding the stochastic valence term, which has a continuous probability distribution, introduces continuity into the expected vote-share functions of the opposing parties and by so doing eliminates the possibility of a vote cycle. Equilibrium also requires concavity of these objective functions, which here is assured by the form of the utility function.

${ }^{23}$ On the other hand, if society is on the upward sloping part of the trade-off, additional constraints on public policy of this sort may reduce social welfare along with coercion.

${ }^{24}$ See, for example, Boadway and Marchand (1995) on incentive compatibility and public expenditure and Hettich and Winer $(1988,1999)$ on the formation of tax structure. Compared to the existing literature, a new element in the work on tax structure will be preferences for public goods, because coercion depends in part on such preferences.

${ }^{25}$ Yitzaki (1979) and Hettich and Winer (1999) have dealt with tax complexity, but not in a framework that explicitly acknowledges coercion.

${ }^{26}$ For reviews of the literature, see Wildwasin (2006) and Wilson (1999). Pennock (1959) analyzed the relationship between majority rule and federalism, arguing that decentralization increases the total number of citizens in a majority coalition. However, although this suggests that decentralization reduces coercion, he did not measure coercion formally nor integrate efficiency into his argument.

${ }^{27}$ To derive (A2), note that the analogue to first order condition (3) when coercion constraints apply to individuals is $\sum_{j}\left(1+\kappa_{j}\right) \lambda_{j} m_{j}=\mu\left[P-t \sum_{j} W_{j}\left(\partial H_{j} / \partial G\right)\right]$. The left-hand side of this can be written as $\sum_{j}\left(1+\kappa_{j}\right) \lambda_{j} m_{j}=\sum_{j} \lambda_{j} m_{j}+\sum_{j} \kappa_{j} \lambda_{j} m_{j}$. Recall that $\kappa, \lambda$, and $m$ are the means of $\kappa_{j}, \lambda_{j}$, and $m_{j}$, respectively: $\operatorname{cov}\left(\kappa_{j} \lambda_{j}\right)=(1 / N) \sum_{j}\left(\lambda_{j}-\lambda_{j}\left(m_{j}-m\right)\right.$ and $\operatorname{cov}\left(\kappa_{j} \lambda_{j} m_{j)}=(1 / N) \sum_{j}\left(\kappa_{j}-\kappa\right)\left(\lambda_{j}-\lambda_{j}\left(m_{j}-m\right)\right.\right.$. Manipulating the covariances and using the new first order condition yields intermediate steps: $\sum_{j} \lambda_{j} m_{j}=N \sigma_{\lambda m}^{2}+\lambda \sum_{j} m_{j}$ and $\sum_{j} \kappa_{j} \lambda_{j} m_{j}=\left[\kappa \lambda \sum_{j} m_{j}+N\left(\kappa \sigma_{\lambda m}^{2}+\lambda \sigma_{\kappa m}^{2}+m \sigma_{\lambda \kappa}^{2}+\sigma_{\kappa \lambda m}^{2}\right)\right]$.

${ }^{28}$ To proceed, one multiplies the analogue to (1) for individual constraints by $(1 / \mathrm{N})$ and that for (2) by $\left(\sum_{j} W_{j} H_{j} / N^{2}\right)$ and subtracts the latter from the former. The left-hand side of the result involves the distributions of three variables: the individual coercion constraint $\kappa_{j}$, the marginal utility of income $\lambda_{j}$, and income $Y_{j}$. Similarly, the right-hand side features the individual coercion constraint $\kappa_{j}$, the marginal utility of the tax share $\psi_{j}=-\lambda *_{j} P G^{*}$, and the marginal tax share, $q_{j}=\left[\left(\partial \tau_{j} / \partial t\right)+\left(\partial \tau_{j} / \partial a\right) Y\right]$, as well as the effect of income taxation on labor supply. Applying the definitions of covariances in the text then yields (A3). 